\title{
CURSINHO POPULAR E COMPETÊNCIAS MATEMÁTICAS: IMPACTO NO ACESSO AO ENSINO SUPERIOR
}

\section{A CRAM COURSE FOR DISADVANTAGED STUDENTS: THE IMPACT OF MATHEMATICAL SKILLS ON HIGHER EDUCATION ACCESS}

\author{
Ronaldo André Lopes* \\ ORCID: https://orcid.org/0000-0001-7215-7101 \\ Andréa Cardoso** \\ ORCID: https://orcid.org/0000-0002-3945-0266
}

\section{RESUMO:}

No âmbito da extensão universitária, os cursinhos populares têm a missão de promover o ingresso ao ensino superior público, combatendo desigualdades associadas a esse processo. Nesse sentido, para se conquistar uma vaga na universidade pública, é fundamental conhecer as habilidades matemáticas avaliadas pelo ENEM. Assim, o Curso Preparatório para o ENEM, estudado neste trabalho, visa fornecer às camadas populares mais oportunidades de acesso à universidade, contribuindo para seu desenvolvimento intelectual e social. $\mathrm{O}$ objetivo deste estudo é discutir o nível de conhecimento matemático dos cursistas e a importância atribuída a ele para se ingressar no ensino superior. A pesquisa é do tipo participante, sendo um estudo de caso realizado por questionário. Conclui-se, por fim, que a participação no Curso Preparatório impacta positivamente a relação dos estudantes com a Matemática, aumentando sua nota média. Além disso, observa-se o papel essencial do estudo da Matemática, independentemente do curso universitário escolhido pelos alunos.

Palavras-chave: Educação; Ensino médio; Educação matemática.

Data recebimento: $30 / 05 / 2020$

\begin{abstract}
:
As university extension programs, cram courses for disadvantaged students have the mission of promoting greater access to higher education. Knowing the mathematical skills evaluated by the ENEM is essential for these students to accomplish their goals of getting into a public university. The ENEM Cram Course studied in our research aims to create more opportunities for candidates from a lower social-economic class to access higher education. The purpose of this study is to discuss these students' level of mathematical knowledge, and to highlight the importance of this knowledge as they embark on the process of entering a university. The research, a case study classified as "participant", was carried out through a questionnaire. We concluded that the cram course has positive impacts on the candidates' relationship with mathematics, and that their average grades increased. We also observed that the study of mathematics is essential, regardless of the course chosen by the students.
\end{abstract}

Keywords: Education; High school; Mathematical education.

\footnotetext{
* Aluno de Mestrado da Universidade Federal de Alfenas (UNIFAL), Alfenas - MG, Brasil. E-mail: ronaldo-1109@ hotmail.com

** Professora da Universidade Federal de Alfenas (UNIFAL), Alfenas - MG, Brasil. E-mail: andreac74@uol.com.br
} 


\section{Introdução}

No Brasil, os dados revelam que apenas $14 \%$ da população jovem ingressa no ensino superior, o que é considerado insatisfatório em comparação com outros países da América Latina, América do Norte e Europa (OLIVEIRA; OLIVEIRA, 2011).

Camargo (2009) argumenta que cursinhos populares são o resultado da organização da sociedade civil, a partir de 1950, para atender uma crescente demanda de uma nova população, que começava a obter o certificado de nível médio. Verifica-se considerável expansão na década 1990 e posteriores, consolidando os cursinhos populares como ações afirmativas para enfrentar a desigualdade de acesso ao ensino superior público brasileiro (ROSEMBERG, 2009).

Neste contexto, nos anos 2000 inicia suas atividades o Curso Preparatório da UNIFAL-MG, popularmente conhecido na cidade e região como Cursinho da UNIFAL. Inicialmente, o Cursinho é um pequeno projeto de extensão, entretanto, ao longo do tempo agrega atividades, ampliando seus objetivos e também o número de participantes para tornar-se um dos maiores programas de extensão da Universidade. O Programa abrange atividades educacionais e tem como objetivos primordiais desenvolver ampla relação com o conhecimento e contribuir para a formação no plano cognitivo e social do educando, visando aumentar as chances de acesso das camadas populares das regiões atendidas ao ensino superior.

Ao longo do tempo, o Cursinho vem modificando seu modus operandi para adaptar-se à realidade objetiva e ao público atendido. Uma mudança significativa ocorre em 2010, com o direcionamento das atividades didáticas junto aos cursistas exclusivamente para o Exame Nacional do Ensino Médio (ENEM). Assim, o próprio nome do projeto muda, doravante denominado Curso Preparatório para o ENEM da UNIFAL-MG.

Neste trabalho, optamos pelo termo cursista, pois aluno e estudante não refletem as discussões levantadas na pesquisa. Isso porque aluno remete àquele que tem um preceptor, enquanto estudante àquele que estuda e tem amor pelo aprendizado. Logo, nota-se que esses dois termos necessitam de ações do indivíduo, que não necessariamente são impostas ou cobradas pelo Cursinho.

O ENEM foi criado em 1998, com o intuito de avaliar o desempenho dos estudantes brasileiros ao final do Ensino Básico, principalmente dos concluintes do Ensino Médio e que almejam uma vaga no Ensino Superior (BRASIL, 2015). Todavia, o Exame assumiu outro papel no âmbito da educação a partir de 2009, com foco na classificação em detrimento da avaliação. Na prova do ENEM, os conhecimentos matemáticos aparecem como uma área exclusiva. Desse modo, Matemática e suas Tecnologias representa um quinto da nota final do candidato, além disso, a nota da área de Matemática tem impacto relevante no acesso aos cursos mais concorridos das universidades federais, mesmo naqueles sem grande correlação com a própria área. 
A matemática é comumente considerada complexa e excludente pelos estudantes das escolas públicas brasileiras. Dessa forma, as habilidades avaliadas no ENEM relacionadas à área de Matemática e suas Tecnologias exercem influência significativa na disputa por uma vaga no ensino superior.

Nesse sentido, surge o seguinte questionamento: Qual é o impacto do Cursinho na importância atribuída pelos estudantes à Matemática e suas Tecnologias na nota final do ENEM? Para tanto, o objetivo deste trabalho é discutir a relação entre o nível de conhecimento matemático dos cursistas e suas percepções do impacto deste na realização do sonho de ingresso à universidade.

\section{Matemática no ENEM como elemento de exclusão}

Segundo Luckesi (1995), o ato de avaliar assumiu a função de classificação em detrimento do diagnóstico, ou seja, houve uma transição na funcionalidade da avaliação escolar. Isso é evidente na utilização do ENEM, que inicialmente objetivava avaliar o desempenho estudantil e, atualmente, é um método de classificação, em que o conhecimento é transformado em número e culmina em um ranking de melhores notas e na competição entre os participantes por vagas no ensino superior.

Atualmente, o ENEM é utilizado pela maioria das universidades, sendo um critério de seleção para os estudantes ingressarem nas Instituições de Ensino Superior (IES). No Brasil, aproximadamente 500 universidades adotam o resultado do ENEM como critério de seleção e ocupação das vagas em cursos de graduação (BRASIL, 2015), sendo 128 instituições públicas através do Sistema de Seleção Unificada (SISU). Essa forma de ingresso no ensino superior pode ser atrelada ao exame vestibular em alguns casos, mas na maioria das universidades o ENEM é a única forma de ingresso. No contexto das universidades privadas, o resultado deste exame pode ser utilizado como forma de concorrer às vagas de programas de financiamento, como, por exemplo, o Programa Universidade para Todos (PROUNI) e o Fundo de Financiamento Estudantil (FIES).

Os conteúdos abordados neste exame são divididos em cinco grandes áreas do conhecimento, quais sejam: Redação (RE), Ciências da Natureza e suas Tecnologias (CN), Ciências Humanas e suas Tecnologias $(\mathrm{CH})$, Linguagens, Códigos e suas Tecnologias (LC) e Matemática e suas Tecnologias (MT). É, pois, necessário compreender como o ensino de Matemática nas escolas públicas estaduais brasileiras tem afetado as notas obtidas por seus estudantes egressos na área MT e, consequentemente, o impacto na concorrência por uma vaga no ensino superior.

A natureza complexa e excludente da Matemática, atribuída por muitos estudantes, está ligada ao desenvolvimento de ansiedade e outras condições negativas decorrentes da 
relação estudante-disciplina (CORREA; MACLEAN, 1999). Além disso, como repulsa à disciplina, diversos estudantes têm um bloqueio com a Matemática, que resulta no descaso e desinteresse em relação ao conteúdo. Como consequência, poucos acreditam que seja possível superar os traumas e adquirir conhecimentos que possam culminar na melhoria de desempenho na Prova de Matemática do ENEM ou outros vestibulares.

Segundo Kato (2011), os cursinhos populares são espaços não-formais de ensino, que propiciam um processo de ensino-aprendizagem e experiências antes inacessíveis pelos grupos beneficiados. Considera-se educação não-formal "toda atividade educacional organizada, sistemática, executada fora do quadro do sistema formal para oferecer tipos selecionados de ensino a determinados subgrupos da população" (LA BELLE, 1986). Os cursinhos, ademais, envolvem seus participantes em um meio com riqueza cultural e que possibilita uma aproximação dos indivíduos com os cursos de graduação. Por vezes, este tipo de ação é a única possibilidade viável para que pessoas egressas de escolas públicas, de baixa renda e vulnerabilidade social tenham contato com o conhecimento exigido em exames de acesso ao ensino superior, como o ENEM.

De acordo com os dados divulgados pelo Instituto Nacional de Estudos e Pesquisas Educacionais Anísio Teixeira (BRASIL, 2020), a proficiência média na prova de MT no ENEM foi de 518,5 em 2017, subindo para 535,5 em 2018, caindo para 523,1 em 2019. Entretanto, a nota média em MT oculta uma perversa realidade, a diferença da média calculada separadamente de escolas das redes estaduais e privada de ensino no país. A partir do tratamento dos dados oficiais do ENEM de 2017, concluiu-se que a média das escolas estaduais é 501,06, enquanto das escolas privadas é 591,25 pontos (SALDANÃ; TAKAHASHI; GAMBA, 2018).

Existe também diferença nas médias obtidas nas outras áreas, contudo é na Matemática a maior diferença, chegando a gritantes 90 pontos na média. Assim, evidencia-se a redução de oportunidades para o estudante egresso da rede estadual de ensino em virtude de uma trajetória escolar marcada por um ensino que carece de qualidade. Ademais, constatouse que $80 \%$ das escolas da rede estadual de ensino têm a média das notas obtidas por seus egressos na prova de Matemática abaixo da média nacional, enquanto o mesmo índice é de apenas $9 \%$ para a rede privada.

\section{Aspectos Metodológicos}

O desenvolvimento do programa ocorre nos três campi da Universidade Federal de Alfenas (UNIFAL-MG), integrando projetos que, anteriormente, eram independentes e isolados na instituição. 
A equipe do programa é composta por estudantes de graduação, que atuam em sua maioria como professores e alguns como gestores. Esses discentes são bolsistas da Pró-Reitoria de Extensão (PROEX) ou voluntários. Há ainda um grupo de docentes da universidade que atua como professores coordenadores dos projetos e cursos do programa.

O cursinho é ofertado de forma gratuita, visando atender indivíduos egressos de escolas públicas ou da Educação de Jovens e Adultos (EJA), bem como pessoas de baixa renda de Alfenas, Poços de Caldas, Varginha e suas microrregiões. O maior dos projetos está no campus sede, denominado Cursinho Popular Êxito, que atende 270 cursistas, divididos em três turmas, uma no período matutino e duas no noturno. Para a seleção dos cursistas, além dos critérios de escolaridade e renda, leva-se em consideração a idade do candidato e o ano de conclusão do Ensino Médio.

Nesta pesquisa, como público-alvo considerou-se apenas os 45 participantes que frequentaram as atividades até o fim do projeto Cursinho Popular Êxito em 2018. De acordo com a classificação de Cervo, Bervian e Silva (2007), esta pesquisa se caracteriza como um estudo de caso, pois envolve um estudo profundo e exaustivo sobre o impacto do conhecimento matemático na realização do sonho de ingresso à Universidade de um grupo específico e delimitado.

Para compreender a relação dos cursistas com a matemática, foi utilizado um questionário fechado, contendo 22 afirmações sobre suas crenças acerca desta disciplina. Após a aplicação do questionário, os dados obtidos foram tabulados em uma planilha eletrônica para serem analisados, quantitativa e qualitativamente.

Ainda tendo como base Cervo, Bervian e Silva (2007), a abordagem utilizada nesta pesquisa pode ser considerada quantitativa, uma vez que considera as respostas ao questionário fechado, transformando-as em dados numéricos para fazer classificação e análise. E, em outros aspectos, é também qualitativa, pois busca compreender os aspectos que levam os estudantes à percepção da importância da Matemática no desempenho no ENEM, ou seja, às crenças acerca de tal disciplina. Ademais, esta é considerada uma pesquisa participante, porque, quanto aos seus procedimentos técnicos, se desenvolve a partir da interação entre os pesquisadores e o público-alvo. Aqui, os pesquisadores são, respectivamente, professor e coordenador da área de Matemática.

\section{Influência da nota de Matemática e suas Tecnologias (MT) no acesso ao ensino superior}

Com base nas respostas dos 45 participantes desta pesquisa, constatou-se que aproximadamente $65 \%$ almejavam uma vaga em cursos de graduação da própria UNIFALMG. Além disso, dos cursos escolhidos, $80 \%$ pertenciam à área da saúde. Esse resultado está diretamente ligado a aspectos culturais da microrregião à qual a universidade pertence. 
Os primeiros cursos da UNIFAL-MG foram Farmácia e Odontologia, que atualmente têm mais de 100 anos. Assim, a demanda por estes cursos é tradicionalmente elevada. Em consequência da primazia por esses cursos, os candidatos acreditam que a Matemática não tem relevância, sendo insignificante sua nota em MT na concorrência por uma vaga.

Nesta pesquisa, os cursos mais desejados pelos cursistas foram Odontologia e Medicina. Dessa forma, optamos por fazer um recorte sobre o curso de Odontologia, que é considerado um dos cursos de grande prestígio social nas universidades públicas e os resultados podem se expandir para outros cursos com características semelhantes.

Segundo Oliveira et al. (2008), os cursos que possuem maior prestígio nas universidades são ocupados por uma elite econômica e privilegiada culturalmente, em sua maioria. Isso reforça ainda mais a necessidade de que o Cursinho corrobore na busca e realização dos sonhos dos cursistas.

Particularmente, a UNIFAL-MG dispõe de um termo de adesão ao SISU que estabelece as notas mínimas necessárias para concorrer às vagas dos cursos de graduação e os pesos para cada área do conhecimento, ambos com base nos resultados obtidos no ENEM. A Tabela 1 exibe estes dados:

Tabela 1 - Notas mínimas e pesos utilizados nos cursos de Odontologia da UNIFAL-MG em 2018 por área do conhecimento do ENEM.

\begin{tabular}{|l|c|c|}
\hline \multicolumn{1}{|c|}{ Área do Conhecimento } & Peso & Nota Mínima \\
\hline Redação & 3 & 600 \\
\hline Ciências da Natureza & 3 & 400 \\
\hline Ciências Humanas & 2 & 350 \\
\hline Linguagens e Códigos & 3 & 400 \\
\hline Matemática & 2 & 400 \\
\hline
\end{tabular}

Fonte: Universidade Federal de Alfenas (2018).

No curso de Odontologia, são ofertadas 50 vagas em cada semestre, sendo $50 \%$ para ampla concorrência e a outra metade destinada a estudantes beneficiários de ações afirmativas, seguindo os critérios estabelecidos pela Lei $\mathrm{n}^{\circ}$ 12711/2012. De acordo com as diretrizes do Programa, todos os cursistas são egressos de escolas públicas, majoritariamente estaduais, logo, eles podem, opcionalmente, concorrer às vagas reservadas pela Lei de Cotas, geralmente amparados pelo fator renda.

Lopes, Silva e Ferreira (2020) destacam que a nota de corte no curso de Odontologia em 2018 foi de 667,4 na categoria L5, que contempla os cursistas, e de 694,31 na ampla concorrência, e que essa nota será similar nos próximos anos. Além 
disso, os autores afirmam que as cotas têm desempenhado papel importante no ingresso em cursos mais concorridos como Odontologia e Medicina na UNIFAL-MG e que, no curso de Odontologia, apenas $26 \%$ dos estudantes cotistas ingressariam sem as vagas reservadas. Isso denota a importância, por exemplo, de um cursinho popular, que vise combater a desigualdade entre as notas de estudantes de escolas públicas e privadas.

Considera-se então que a nota mínima da categoria ampla concorrência $(694,31)$ seja a nota necessária para que o cursista ingresse em Odontologia, visto que essa foi a nota de corte do processo seletivo de 2018.

Assim, é possível prever a nota final (NF) mínima necessária para que o cursista consiga uma vaga em um dos dois cursos mais concorridos desta universidade. A previsão foi realizada, opcionalmente, com base no curso de Odontologia, pois esse curso é menos concorrido que o de Medicina, o que permite inferir que seria necessária uma nota ainda maior em Matemática para ingressar neste último.

Para o curso de Odontologia, a NF é dada a partir da média ponderada de cada componente, de acordo com os pesos apresentados na Tabela 1, por:

$$
\mathrm{NF}=\frac{3(\mathrm{RE}+\mathrm{CN}+\mathrm{LC})+2(\mathrm{CH}+\mathrm{MT})}{13}
$$

De acordo com a fórmula, um candidato hipotético à vaga no curso de Odontologia mesmo que obtivesse 700 pontos em todas as áreas, exceto em MT, não ingressaria no curso caso tivesse nota inferior ou igual a 600 pontos na prova de Matemática do ENEM.

Como já mencionado, o público-alvo do cursinho é proveniente de escolas públicas, sendo a maioria oriunda do ensino médio em escolas públicas estaduais. O município de Alfenas, que atende grande parte dos cursistas, tem seis escolas públicas estaduais de ensino médio. Destas, apenas duas têm as médias da prova de Matemática do ENEM 2018 divulgadas, sendo elas 530,44 pontos e 499,19 pontos. Disto deduz-se que a média do cursista esteja em torno de 515 pontos, portanto muito aquém da nota mínima estimada.

\section{Visão dos cursistas em relação à Matemática}

Para compreender a visão dos cursistas sobre a Matemática, foram utilizadas todas as afirmações do questionário, considerando-se duas delas para esta análise: "A minha relação com a Matemática é boa" e "É importante aprender Matemática". O Gráfico 1 exibe as respostas dos cursistas: 
Gráfico 1 - Relação dos cursistas com a Matemática

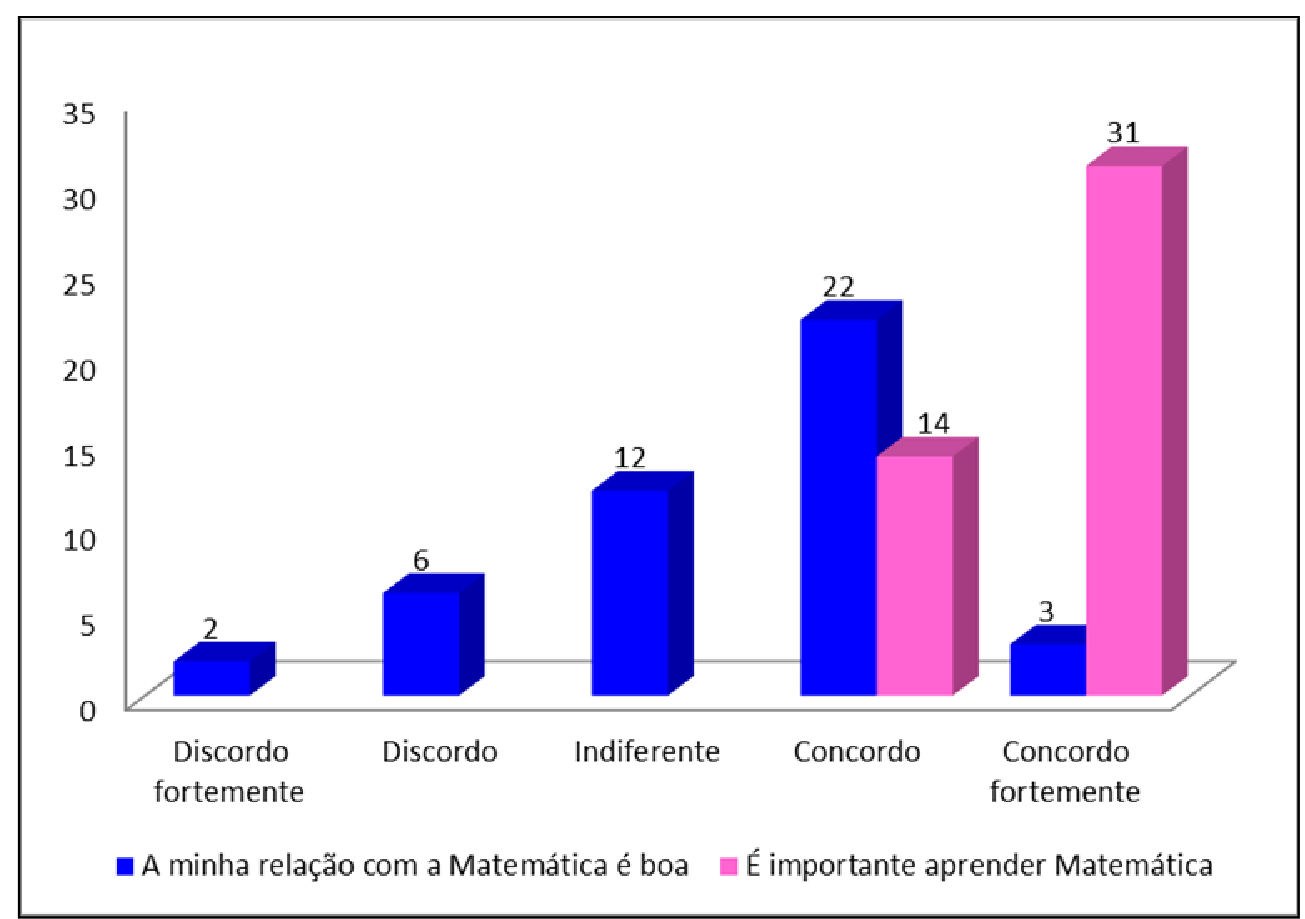

Fonte: Elaborado pelos autores.

As respostas evidenciam que todos os cursistas consideram importante aprender Matemática. Contudo, aproximadamente $44,5 \%$ dos participantes afirmaram que sua relação com a Matemática não é boa ou se mostraram indiferentes em relação a isso. Logo, conclui-se que, mesmo sabendo da importância da disciplina, grande parte dos cursistas não tem boa relação com a Matemática, o que é um obstáculo para o desenvolvimento das habilidades matemáticas necessárias para obter a nota suficiente para ingresso no curso almejado.

Uma das afirmações contidas no questionário buscou compreender se o Cursinho impactou positivamente a relação deles com a Matemática. O Gráfico 2 exibe as respostas obtidas: 
Gráfico 2 - Respostas dadas pelos cursistas à afirmação "O Curso Preparatório para o ENEM impactou positivamente minha relação com a Matemática”.

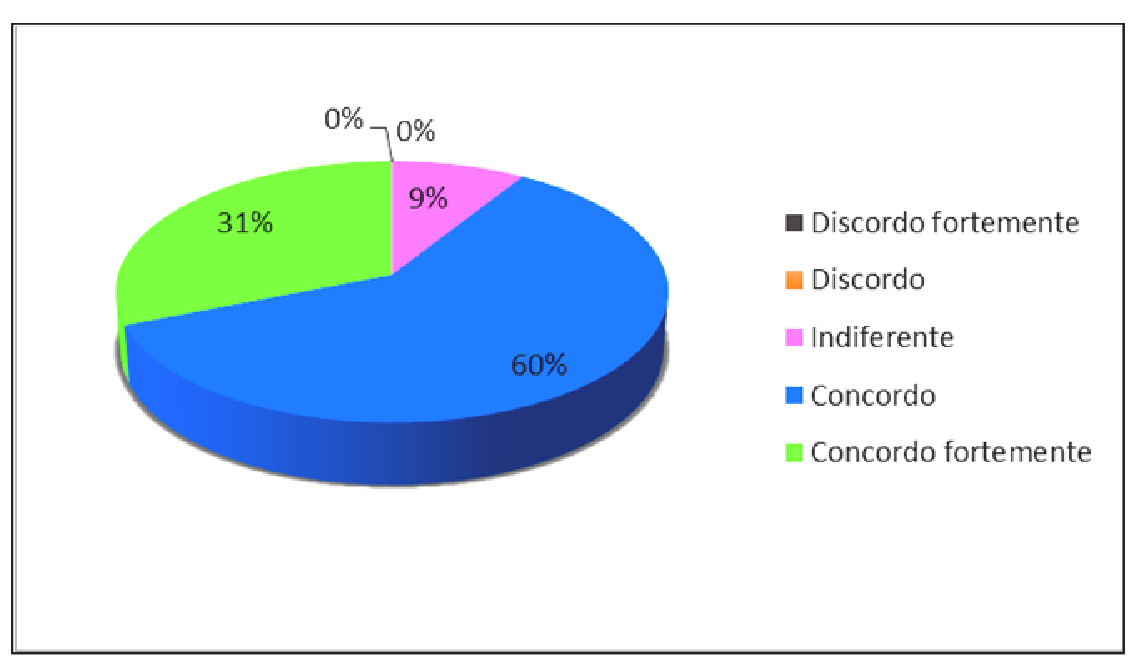

Fonte: Elaborado pelos autores.

Com base nas respostas obtidas, conclui-se que houve um impacto positivo na relação da maioria dos cursistas com a Matemática. Alguns poucos alunos mostraram-se indiferentes quanto a este impacto.

O real impacto do Cursinho no desempenho dos cursistas somente pode ser medido comparando-se as notas obtidas na Prova de Matemática em anos consecutivos. Porém, somente 26,7\% dos participantes informaram as notas do ENEM em 2017 e 2018. A média dos cursistas nestes dois anos foi 503,8 e 537,15 pontos, respectivamente. Mesmo com uma amostra reduzida, pudemos constatar o aumento da média nas notas e associá-lo à participação no Cursinho. Entretanto, encontramos dificuldade em obter informações sobre as notas, visto que muitos cursistas se mostram desconfortáveis em socializar seus resultados. Isso pode ser um reflexo da resistência em expor sua real relação com a Matemática, evidenciando o conflito.

Para associar as crenças dos cursistas sobre a Matemática e a expectativa em relação às notas do ENEM, foi utilizada a seguinte pergunta no questionário: "Qual nota você considera satisfatória em Matemática e suas Tecnologias na prova do ENEM?". Em resposta a essa questão, $27 \%$ dos cursistas afirmaram que a nota poderia ser inferior a 600 pontos e $67 \%$ acreditam que a nota satisfatória está compreendida entre 600 e 800 pontos. Desse modo, percebe-se que a maioria dos cursistas é ciente da necessidade de uma nota mínima para o ingresso no curso de graduação desejado. Ainda assim, os cursistas que acreditavam na suficiência de notas inferiores a 600 pontos exibem uma ausência de conhecimento sobre as notas necessárias para os cursos almejados. 
Com base nisso, os cursistas podem ser subdivididos em dois grupos. O primeiro grupo contempla indivíduos que não sabem que a nota satisfatória em Matemática no ENEM está entre 600 e 800 pontos e precisam ser esclarecidos sobre isso. E o outro grupo é composto por cursistas que sabem qual deve ser a nota satisfatória em Matemática, mas precisam melhorar as notas obtidas em exames anteriores, a fim de alcançar a nota mínima estimada.

Além disso, na afirmação "Considero que dedico tempo suficiente para estudar Matemática", aproximadamente $49 \%$ dos participantes discordaram ou se mostraram indiferentes à afirmação. Logo, quase metade dos cursistas confirma que não dedica o tempo necessário para o estudo desta disciplina.

Sendo assim, observa-se que os cursistas, de modo geral, sabem da importância da Matemática, compreendem a necessidade de uma boa nota nessa área no ENEM, porém não dedicam tempo suficiente para estudá-la. Com isso, o resultado esperado por eles se torna incoerente, pois sem dedicação ao seu estudo, o êxito dificilmente será alcançado. Já no caso dos cursistas que não sabem qual deve ser a nota satisfatória e dedicam pouco tempo ao estudo, são necessárias atividades que promovam a conscientização sobre o tema pelo programa. Percebe-se ainda que o Cursinho impacta positivamente a relação dos cursistas com a Matemática.

\section{Considerações Finais}

Uma relação conflituosa com a Matemática acompanha o egresso da rede estadual de ensino, o que representa um obstáculo a ser superado na luta por uma vaga no ensino superior, principalmente se o curso desejado estiver entre os mais concorridos. Constatou-se que os cursistas reconhecem a importância da Matemática, mas não estabelecem uma conexão suficiente com a disciplina, o que afeta seu progresso e, consequentemente, sua nota no ENEM. Dessa forma, evidencia-se uma flagrante contradição entre o desejo e a busca pela conquista das metas preestabelecidas.

O sonho de acesso à universidade pelas classes populares precisa ser transformado em projeto, com etapas e metas a serem planejadas e cumpridas. E para alcançar as metas estabelecidas, a Matemática é uma etapa essencial, independentemente do curso escolhido.

Espera-se que a presente pesquisa inspire outros trabalhos relacionados à temática, possibilitando a compreensão da relação dos estudantes com a Matemática, como também com outras disciplinas. 


\section{Referências}

BRASIL. ENEM. INEP. Ministério da Educação, 2015. Disponível em: <http://portal.inep.gov.br/web/guest/enem>. Acesso em: 15 maio 2020.

BRASIL. Microdados. INEP. Ministério da Educação, 2020. Disponível em: < http://inep.gov.br/web/guest/microdados>. Acesso em: 15 maio 2020.

CAMARGO, F. F. Cursinhos pré-vestibulares populares e o caso da Unesp: alguns condicionantes à sua criação e transformação. Dissertação (Mestrado) - Unesp Araraquara, Araraquara, 2009.

CERVO, A. L.; BERVIAN, P. A.; SILVA, R. Metodologia Científica. 6.ed. São Paulo: Pearson Prentice Hall, 2007.

CORREA, J.; MACLEAN, M. Era uma vez ... um vilão chamado matemática: um estudo intercultural da dificuldade atribuída à matemática. Psicologia Reflexão e Crítica, v. 12, n.1, 1999.

KATO, D. S. O papel dos cursinhos populares nos acessos e mudanças de perspectivas de seus participantes. Cadernos CIMEAC, v. 1, p. 5-24, 2011.

\section{LA BELLE, T. J. Nonformal Education in Latin America and the Caribbean:}

Stability, Reform, Or Revolution? Austin: Praeger, 1986.

LOPES, R. A.; SILVA, G. H. G.; FERREIRA, E. B. O impacto da Lei de Cotas na Universidade Federal de Alfenas em 2018. Alfenas: SIBI/UNIFAL-MG. E-book 168 p. Disponível em: <https://www.unifal-mg.edu.br/bibliotecas/system/files/imce/Ebookimpacto.pdf>. Acesso em: 18 maio 2020.

LUCKESI, C. C. Avaliação da aprendizagem escolar. São Paulo: Cortez, 1995.

OLIVEIRA, J. F.; CATANI, A. M.; HEY, A. P.; AZEVEDO, M. L. N. Democratização do acesso e inclusão na educação superior no Brasil. In: BITTAR, M.; OLIVEIRA, J. F.; MOROSINI, M. (org.). Educação Superior no Brasil - 10 anos pós-LDB. Brasília: INEP, 2008. p. 71-88.

OLIVEIRA, G. C. B.; OLIVEIRA, P. T. Acesso de camadas populares ao ensino superior: um levantamento socioeconômico de estudantes em uma faculdade recentemente instalada no interior de São Paulo. In: CONGRESSO DO INSTITUTO FRANCO-BRASILEIRO DE ADMINISTRAÇÃO DE EMPRESAS, 6., 2011, Franca. [Anais...]. Franca (SP), 2011. 
ROSEMBERG, F. Ação afirmativa no Ensino Superior brasileiro: pontos para reflexão. In: Universidade Federal de São Carlos. Programa de Ações Afirmativas: processo de construção. São Carlos, 2009. p. 1-25. Disponível em: <https://www.geledes.org.br/wpcontent/uploads/2014/09/AcaoO_AFIRMATIVA_NO_ENSINO.pdf $>$. Acesso em: 25 maio 2020 .

SALDANÃ, P.; TAKAHASHI, F.; GAMBA, E. Matemática agrava abismo entre escolas públicas e privadas no ENEM. Folha de São Paulo. São Paulo, 9 jul. 2018. Disponível em: <https://www1.folha.uol.com.br/educacao/2018/07/matematica-agrava-abismo-entreescolas-publicas-e-privadas-no-enem.shtml>. Acesso em: 16 maio 2020.

UNIVERSIDADE FEDERAL DE ALFENAS. Edital n. 03/2018. Processo Seletivo de ingresso nos cursos presenciais de graduação da UNIFAL-MG por meio do Sistema de Seleção Unificada SISU - Edição 1/2018. Alfenas, 2018. 